\title{
Die Frau von W. Die Venus von Willendorf, ihre Zeit und die Geschichte(n) um ihre Auffindung
}

Jean-Laurent Monnier

\section{(2) OpenEdition}

\section{Journals}

Édition électronique

URL : http://journals.openedition.org/rao/939

DOI : $10.4000 /$ rao.939

ISBN : 978-2-7535-1609-0

ISSN : $1775-3732$

\section{Éditeur}

Presses universitaires de Rennes

\section{Édition imprimée}

Date de publication : 31 décembre 2009

Pagination : 331

ISBN : 978-2-7535-1086-9

ISSN : 0767-709X

\section{Référence électronique}

Jean-Laurent Monnier, «Die Frau von W. Die Venus von Willendorf, ihre Zeit und die Geschichte(n) um ihre Auffindung », Revue archéologique de l'Ouest [En ligne], 26 | 2009, mis en ligne le 31 décembre 2011, consulté le 03 décembre 2020. URL : http://journals.openedition.org/rao/939 ; DOI : https://doi.org/ 10.4000/rao.939 


\section{Analyses d'ouvrages}

ANTL-WeISER, W., 2008 - Die Frau von W. Die Venus von Willendorf, ihre Zeit und die Geschichte(n) um ihre Auffindung, Vienne, éditions des Musées d'Histoire naturelle (publication du département de Préhistoire), 207 p. (ISBN 978-3-902421-25-8).

Cet ouvrage consacré à la Vénus de Willendorf est publié par les éditions des Musées d'Histoire naturelle d'Autriche. Il est destiné à un large public curieux et intéressé par les origines de l'art et par la préhistoire ancienne en général. Le livre est largement documenté et son maquettage est particulièrement agréable. Les illustrations abondantes sont de grande qualité et font appel à des documents rarement accessibles. Elles créent une " ambiance " très vivante, à la manière d'une enquête, concernant cet objet devenu mythique et les conditions de sa découverte.

Mise au jour en 1908 lors de fouilles dans une ancienne briqueterie, la statuette est sculptée dans un calcaire oolithique et mesure $11 \mathrm{~cm}$. Cette figuration féminine est caractérisée par sa forte obésité avec les bras posés sur d'énormes seins. Le visage est caché par ce qui paraît être un enroulement de tresses. Il se pourrait qu'elle ait été peinte dans les tons rouges car de traces de pigments sont conservés. Attribuée à la période gravettienne, vers 23000 ans, elle est conservée au Musée d'Histoire naturelle de Vienne.

Le premier chapitre, en guise d'introduction, situe cette œuvre d'art paléolithique comme une "icône " du temps présent, tant son image est connue et mise à contribution des circonstances et avec des objectifs parfois surprenants. Ainsi par exemple, la Vénus de Willendorf sert de logo pour les mouvements de revendication de la rondeur féminine qui se sont développés depuis une trentaine d'années.

Le chapitre suivant rappelle le cadre des connaissances sur la préhistoire ancienne en 1908 : d'abord la situation en France, berceau de la Préhistoire, puis celle des recherches en Autriche, suivie d'une présentation du contexte des recherches en grottes, de la géologie, de l'histoire de l'art, de l'anthropologie et de l'ethnologie, avec enfin l'état des connaissances sur les sculptures de formes humaines paléolithiques en 1908.

Le troisième chapitre traite de la découverte de Willendorf et des protagonistes de la fouille en 1908. La présence d'une occupation paléolithique, marquée par des silex taillés, était connue depuis plus de vingt ans lorsque débuta, à l'occasion de la construction d'une ligne de chemin de fer, la fouille qui devait conduire à la découverte. Hommage est rendu aux trois personnalités scientifiques de l'époque, responsables des recherches sur le terrain (le "who is who " à Willendorf en 1908) : Josef Szombathy, Josef Bayer et Hugo Obermaier.
Le quatrième chapitre, illustré de nombreux documents d'époque, décrit la découverte de la vénus le 7 août 1908 par l'ouvrier Johann Veran devant Szombathy et Bayer, mais en l'absence de Obermaier, ce qui entraîna ultérieurement une polémique. Le texte rappelle les conditions de la fouille comparées aux méthodes et techniques actuelles, l'historique de la fouille, les circonstances de la découverte et la première publication concernant précisément la vénus de Willendorf.

Le cinquième chapitre décrit le contexte humain dans lesquelles la statuette de Willendorf a été fabriquée : conditions climatiques (période très froide), environnement végétal et faunique, origine des matériaux utilisés pour la fabrication des outils, évolution technique de l'époque, parures, vêtements et colorants, vie à l'époque des Gravettiens (chasse et alimentation). Le matériau et la fabrication de la statuette sont décrits avec précision, avec des photos très détaillées.

Le sixième chapitre traite de la signification de la vénus de Willendorf : peut-on la considérer comme une œuvre d'art? Elle est mise en parallèle avec les deux autres vénus trouvées à Willendorf, très différentes dans leur conception.

Le septième chapitre est intitulé « La Vénus de Willendorf et la plastique féminine au Gravettien ». La construction et le style de la figuration sont analysés et comparés à celles d'autres " vénus " paléolithiques. Un essai d'interprétation est présenté à partir d'une analyse bibliographique, avec des questions classiques qui restent non ou mal résolues : est-ce réellement une image de la femme gravettienne? Est-ce un symbole de fécondité? Est-ce un hommage à la femme au Gravettien? Est-ce un esprit " protecteur » et la «mère du peuple »? Divinité ou déesse? Etc.

Le huitième chapitre s'intitule «La Vénus de Willendorf et les femmes du Paléolithique ", s'intéressant au statut de la femme au Paléolithique, tandis qu'un dernier chapitre met en avant l'importance du gisement de Willendorf pour la recherche sur le Paléolithique.

L'ouvrage comporte de nombreuses notes et références bibliographiques, ce qui en fait un document scientifique intéressant. Seul problème, la langue allemande n'est pas à la portée du plus grand nombre. Une édition en anglais en faciliterait la diffusion. Des résumés et des légendes bilingues auraient aussi été bien utiles. 